${ }^{6}$ Universite de Lorraine, Nancy, France; ${ }^{7}$ Maartens Kliniek, Nijmegen, Netherlands; ${ }^{8}$ Schlosspark Klinik, Berlin, Germany; ${ }^{9}$ Parker Institute, Copenhagen, Denmark; ${ }^{10}$ Cardiff University, Cardiff, United Kingdom; ${ }^{11}$ UCLA, Los Angeles, United States; ${ }^{12}$ University of the West of England, Bristol, United Kingdom; ${ }^{13}$ Healthy Motivation, Santa Barbara, United States; ${ }^{14}$ University of Sydney, Sydney, Australia

Background: Disease flares in RA are common. The RA Flare Questionnaire (RA-FQ) can be used to identify and quantify flares in rheumatoid arthritis (RA). Objectives: To further explore the psychometric properties RA-FQ, we used Rasch analysis and reviewed results with RA patients research partners (PRPs) and clinicians to gain additional insight into the interpretability, meaningfulness, and utility of results.

Methods: People with RA in observational trials in Canada (CATCH; $n=896$ ) and France (STPR; $n=138$ ), and an RCT in the Netherlands ( $n=178$ ) completed the RA-FQ. RUMM2030 was used to evaluate unidimensionality, targeting of items to people, reliability, response options, redundancy, local dependence, and response bias by sex, across age categories, and by country/language. ROC curves were used to identify sensitivity and specificity across potential threshold values to identify flares in different contexts of use. We reviewed results with RA patients research partners (PRPs) to gain additional insight into the interpretability, meaningfulness, and utility of results. Ten PRPs first completed the questionnaire then reviewed individual and group findings to provide feedback. RA clinicians provided feedback on utility and relevance of proposed cut points to identify flares. Results: Rasch results supported the simple summation of items for a total score ranging from $0-50$. Each item had ordered thresholds and acceptable fit. Reliability, was high ( $\mathrm{PSI}=.91$ ). Items and people covered a continuum ranging from -3.2 to +3.4 logits, and items were well-targeted to respondents. Overall model fit was excellent $\left(x^{2}=31.6, d f=45 ; p=0.935\right)$. There was little evidence of differential item functioning by sex, age, or country/language. Items suggest flare symptoms and impacts increased together showing a consistent story of how individuals experience worsening RA disease activity. Among PRPs, scores ranged from 10 to 41 . There was unanimous agreement from the patients that the story depicted and individual results obtained were easily understood, meaningful, and very reflective of their current state. Many patients noted that beyond clinical trials, the RA-FQ could also enhance communication between doctors and patients at routine visits. Several noted potential applicability in monitoring day-to-day status and with self management. Thresholds for clinically important worsening to identify flare varied by setting, patient population, and context of use.

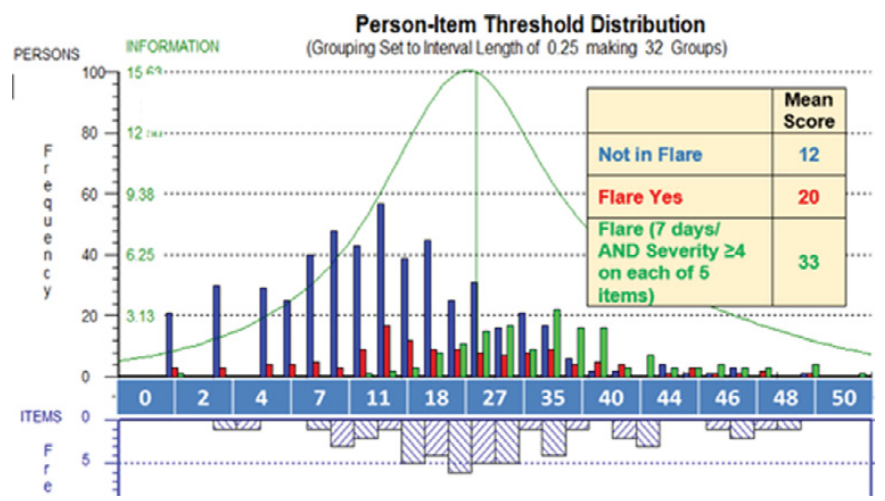

Conclusions: Taken together, results from classical and Rasch analyses support for the robust psychometric properties of the RA-FQ. The 5 -item measure is easy to complete and simple to score. Feedback from RA PRPs and clinicians increase confidence in the relevance, meaningfulness, and easy interpretation of RA-FQ results for clinicians, researchers, and patients.

Disclosure of Interest: None declared

DOI: 10.1136/annrheumdis-2017-eular.5593

\section{SAT0133 SUDOMOTOR DYSFUNCTION IN RHEUMATOID ARTHRITIS PATIENTS IN THE ABSENCE OF TRADITIONAL CARDIOVASCULAR RISK}

T. Syngle ${ }^{1}$, S. Kaur ${ }^{2}$, I. Verma ${ }^{3}$, A. Syngle ${ }^{4} .{ }^{1} \# 547$, Sector $16 D$, Chandigarh, India, Healing Touch Foundation, Chandigarh, India; ${ }^{2}$ Cardio-Rheuma \& Healing Touch City Clinic, Chandigarh; ${ }^{3}$ Maharishi Markandeshwar College of Pharmacy, M.M University, mullana; ${ }^{4}$ Cardio-Rheuma \& Healing Touch City Clinic and Fortis Multi Specialty Hospital, Chandigarh, India

Background: Rheumatoid arthritis (RA) is an autoimmune chronic inflammatory disease associated with cardiovascular autonomic neuropathy. Cardiovascular autonomic neuropathy is a significant risk predictor for sudden cardiac death in rheumatoid arthritis. ${ }^{1}$ Sudomotor dysfunction reflects small fibre neuropathy, cardiovascular autonomic neuropathy and peripheral sympathetic autonomic neuropathy. ${ }^{2}$ However, sudomotor dysfunction and its relationship with inflammatory measures remain unexplored in RA patients in the absence of traditional cardiovascular (CV) risk factors.

Objectives: The aim of present study was to assess the sudomotor function and its association with disease specific measures: ESR, CRP and DAS-28 in RA patients with no apparent conventional cardiovascular risk factor.

Methods: In this cross-sectional study, 60 RA patients fulfilling 2010 Rheumatoid Arthritis Classification Criteria ${ }^{3}$ and 40 age and sex-matched healthy controls were recruited. Sudomotor function was assessed using Sudoscan (Impeto Medical, Paris, France) through measurement of electrochemical skin conductance of hands and feet. ${ }^{2}$ Sudoscan investigates the sweat gland activity and used as a surrogate to study the damage of sympathetic sudomotor nerves in neuropathy. It is an indirect assessment tool of sudomotor function. Inflammatory measures such as ESR and CRP and DAS-28 (disease activity score in 28 joints) were determined.

Results: Rheumatoid arthritis patients had significantly impaired sudomotor function ( $56.90 \pm 12.95$ vs. $76.15 \pm 8.45 \mu \mathrm{s}, p<0.00$, Figure $1 \mathrm{~A}$ ), elevated ESR $(31.30 \pm 12.34$ vs. $16.72 \pm 4.46, p<0.001)$ and $\operatorname{CRP}(10.55 \pm 3.81$ vs. $3.81 \pm 1.03$, $\mathrm{p}=0.002$ ) as compared to healthy controls, respectively. The mean disease duration of RA patients was $9.15 \pm 5.76$ and they had high disease activity (mean DAS-28, 4.60 \pm 1.72$)$. Sudomotor function was found to be inversely correlated with ESR $(r=0.42, p=0.001$, Figure 1B), CRP $(r=0.60, p<0.001$, Figure 1C) and DAS-28 $(r=0.38, p=0.003$, Figure 1D).

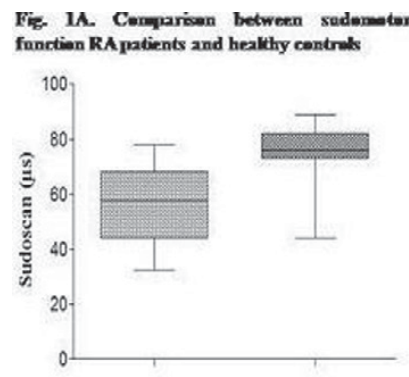

RA
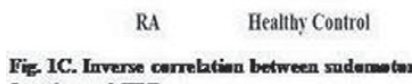

function and CRP

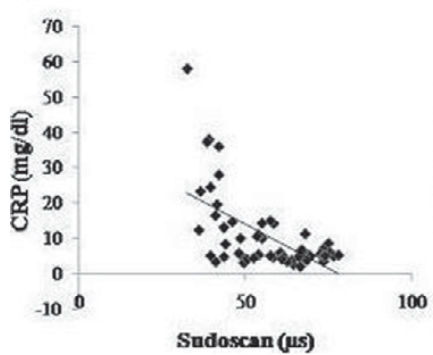

Conclusions: Cardiovascular autonomic neuropathy occurs in RA in the absence of traditional CV risk factors. Sudomotor dysfunction is significantly associated with increased level of ESR, CRP and disease activity suggesting that increased inflammation may cause sudomotor dysfunction.

References:

[1] Milovanovic B et al. Srp Arh Celok Lek 138:26-32.

[2] Mayaudon $\mathrm{H}$ et al. Diabetes Metab. 2010;36:450-54

[3] Aletaha D et al. Arthritis Rheum. 2010;62:2569-81.

Acknowledgements: None.

Disclosure of Interest: None declared

DOI: 10.1136/annrheumdis-2017-eular.4382

\section{SAT0134 DAILY MONITORING OF ARTERIAL STIFFNESS IN WOMEN WITH RHEUMATOID ARTHRITIS}

T.A. Romanova, N.M. Nikitina, A.P. Rebrov. Hospital Therapy Department, State Medical University of Saratov, Saratov, Russian Federation

Background: Patients with rheumatoid arthritis (RA) have an increased risk of cardiovascular (CV) disease. Monitoring of arterial stiffness could be used as an additional tool of cardiovascular risk assessment.

Objectives: of the study is to evaluate the main parameters daily monitoring of arterial stiffness (DMAS) in women with rheumatoid arthritis with or without arterial hypertension $(\mathrm{AH})$.

Methods: DMAS was measured in 63 women with RA (ACR 1987 and/or EULAR/ACR 2010 criteria). The first group involved 39 RA female patients with $\mathrm{AH}$ (mean age $-58.3 \pm 6.08$ years; median of RA duration - $8[4 ; 14]$ years, median of DAS 28- 5.08 [4.04; 5.85]), the second group included 24 women with RA without AH (mean age $55 \pm 7.15$ years; duration of RA is 10 [3; 17] years, mean DAS $28-5.25[4.6 ; 5.7])$

30 women with $A H$ without RA and other joint diseases and 22 healthy females were involved as a controls. Persons with and without RA were comparable 
inconventional cardiovascular risk factors. Exclusion criteria were smoking, diabetes mellitus, symptomatic $\mathrm{AH}$, cardiovascular diseases (except $\mathrm{AH}$ ). DMAS was measured by using the BPlab with technology VASOTENSE (Russian).An index of arterial stiffness (ASI), a daily index of arterial stiffness (AASI), an aortic pulse wave velocity (PWVao), augmentation index (AIX) were measured. All indexes were estimated at day and night hours.

Statistics was performed with STATISTICA 7.0 (StatSoft, USA).

Results: Hypertensive RA patients and AH patients without RA had comparable DMAS parameters (ASI, PWVao, Alx). The AASI index was higher in RA patients without $A H$ versus controls $(0.48 \pm 0.2$ and $0.29 \pm 0.17$, respectively, $p=0.00001)$ and the AASI index was higher in hypertensive RA patients versus AH patients $(0.5 \pm 0.2$ and $0.38 \pm 0.15$, respectively, $p=0.01)$. AASI $>0.07$ revealed at RA patients more often than in controls: at $13.15 \%$ of hypertensive RA patients and at $16.6 \%$ of RA patients without $A H$, respectively, $p<0.05$. The increase of PWVao observed at RA patients frequently than in controls $(p<0.05)$.

Daily index ASI100 was higher in RA patients without $\mathrm{AH}$ than in healthy controls $(121[109.5 ; 139] \mathrm{mmHg}$ vs. $107[103 ; 115] \mathrm{mmHg}, \mathrm{p}=0.014)$.

The increased of $\mathrm{Al} \times 75$ was registered in $25 \%$ of $\mathrm{RA}$ patients without $\mathrm{AH}$ and in $9.09 \%$ of controls $(p=0.08)$. PWVao and average Aix75 correlates with ESR ( $r$ $=0.38$ and $r=0.36$, respectively, $p<0.05)$ in RA patients with AH; AASI correlates with level $\mathrm{C}$-reactive protein $(\mathrm{r}=0.36, \mathrm{p}<0.05)$.

ASI and AASI in RA patients with AH correlates with age (Spearmen's $r=0.41$ and $r=0.36$, respectively, $p<0.05)$, systolic blood pressure $(r=0.76$ and $r=0.65$, respectively, $p<0.05)$; pulse blood pressure $(r=0.77$ and $r=0.43$, respectively, $p<0,05)$.

Conclusions: Arterial stiffness, according to daily monitoring, in RA patients is higher than in hypertensive patients without RA and healthy controls. Arterial stiffness in patients with RA and $A H$ is higher than in patients with RA without $A H$ or AH without RA. Age, systolic blood pressure, pulse blood pressure, high levels of ESR and C-reactive protein associated with increased arterial stiffness in RA patients.

Disclosure of Interest: None declared

DOI: 10.1136/annrheumdis-2017-eular.5683

\section{SAT0135 CARDIOVASCULAR RISK IN RHEUMATOID ARTHRITIS PATIENTS FROM SOUTHERN BRAZIL AND ITS ASSOCIATION WITH SERUM LEVELS AND GENOTYPIC VARIATION OF MANNOSE BINDING LECTIN}

B. Stadler ${ }^{1}$, T.A.F.G. Dos Santos ${ }^{1}$, T. Skare ${ }^{1}$, R. Nisihara ${ }^{1,2}$, R. Petisco ${ }^{3}$, I. Goeldner ${ }^{2}$, S. Utiyama ${ }^{4}$, I.J.T. Messias-Reason ${ }^{2} .{ }^{1}$ Rheumatology Unit, Hospital Universitário Evangelico de Curitiba; ${ }^{2}$ Department of Medical Pathology, Federal University of Paraná; ${ }^{3}$ Evangelic School of Medicine; ${ }^{4}$ Department of Clinical Analysis, Federal University of Paraná, Curitiba, Brazil

Background: The binding lectin mannose (MBL) is a serum protein of collectin family that appears to be involved in the inflammatory process and in the genesis of atherosclerotic disease.

Objectives: To study the association of serum levels of MBL and its genotypic variation with carotid arteries intimal thickness (IMT) in rheumatoid arthritis (RA) patients from Southern Brazil.

Methods: Serum level, MBL genotyping and IMT were studied in 90 RA patients along with their demographic, clinical and laboratory profile. MBL levels were measured in 90 healthy controls.

Results: There was significant difference between mean serum levels of MBL in patients with RA and controls ( $528 \mathrm{ng} / \mathrm{mL}$ vs $937.5 \mathrm{ng} / \mathrm{mL}, p=0.05$, respectively). The median IMT in RA patients was $0.59 \mathrm{~mm}(0.51$ to $0.85 \mathrm{~mm})$. There was no correlation between levels of MBL with disease activity measured by DAS-28 (disease activity score-28), erythrocyte sedimentation rate (ESR), autoantibodies presence or IMT ( $p=N S)$. A negative correlation was found between MBL levels with CRP levels $(\mathrm{p}=0.02)$. The mutation vat codon 54 (variant $\mathrm{B})$ and HYPA haplotype were the most frequent $(67.5 \%$ and $31.7 \%$, respectively) in the RA sample. Dominant genotypes $(\mathrm{A} / \mathrm{A})$ are associated with lower IMT when compared with heterozygotes $(\mathrm{A} / \mathrm{O} ; \mathrm{p}=0.04)$ and homozygous recessive $(\mathrm{O} / \mathrm{O} ; \mathrm{p}=0.05)$. Also dominant genotypes had lower CRP when compared with heterozygous $(p=0.04)$ or with recessive genotypes $(p=0.05)$.
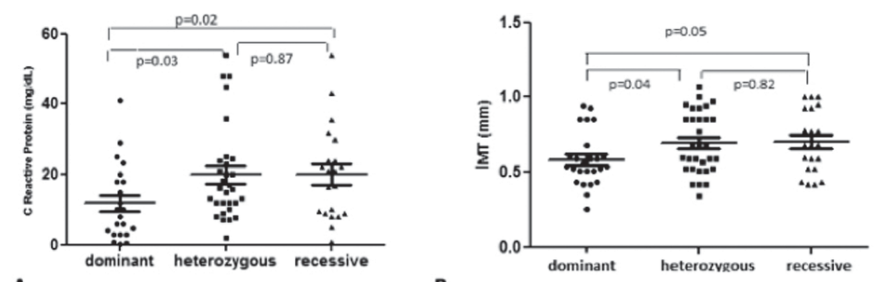

A B THICKNESS (IMT)

Conclusions: RA patients had lower MBL levels than controls. MBL serum levels are negatively associated with CRP; low producers of MBL had increased thickness of the IMT than high producers.
References:

[1] Scarno A, Perrotta FM, Cardini F, Carboni A, Annibali G, Lubrano E, et al. Beyond the joint: Subclinical atherosclerosis in rheumatoid arthritis. World J Orthop [Internet]. 2014;5(3):328-35. Available from: http://www.wjgnet. com/2218-5836/full/v5/.

[2] Ip WK, Lau YL, Chan SY, Mok CC, Chan D, Tong KK, et al. Mannosebinding lectin and rheumatoid arthritis in southern Chinese. Arthritis Rheum. 2000;43(8):1679-87.

[3] J Maury CP, Aittoniemi J, Tiitinen S, Laiho K, Kaarela K, Hurme M, et al. Variant mannose-binding lectin 2 genotype is a risk factor for reactive systemic amyloidosis in rheumatoid arthritis. Jounal Intern Med. 2007;262:466-9.

[4] Graudal NA, Homann C, Madsen HO, Svejgaard A, Jurik AG, Graudal HK, et al. Mannan Binding Lectin in Rheumatoid Arthritis. A Longitudinal Study. J Rheumatol. 1998;25(4):629-35.

[5] Carvalho EG, Utiyama SRR, Kotze LMS, Reason ITM. Lectina ligante de manose (MBL): características biológicas e associação com doenças. Res bras alerg imunopatol. 2007;30(5):187-93.

Disclosure of Interest: None declared

DOI: 10.1136/annrheumdis-2017-eular.6998

\section{SAT0136 ASSOCIATION OF GENOTYPES FOR BCL1 POLYMORPHISM IN THE GLUCOCORTICOID RECEPTOR GENE WITH ISCHEMIC HEART DISEASE IN PATIENTS WITH RHEUMATOID ARTHRITIS}

V.S.S.U. Kmyta, O. Savchenko, L. Prystupa. Internal Medicine Department, 4682, Sumy, Ukraine

Objectives: The objective is to study association of genotypes for Bcl1 polymorphism in the glucocorticoid receptor (GR) gene with ischemic heart disease (IHD) in patients with rheumatoid arthritis (RA).

Methods: 161 subjects with rheumatoid arthritis aged 40 years and older were examined by means of instrumental, clinical and laboratory examinations. Rheumatoid arthritis was diagnosed according to ACR/EULAR Classification Criteria (2010). The IHD diagnosis was verified by means of AHA/ACC guidelines (2012). BCL1 polymorphism in exon 2 was identified using polymerase chain reaction with subsequent analysis of restriction fragment length polymorphism by Fleury I. et al. (venous blood was used as the material for the study). Statistical analysis was performed using SPSS-17 program.

Results: It was revealed that $76(47.2 \%)$ patients had isolated RA (group I), while $85(52.8 \%)$ individuals had RA with concomitant IHD (group II). In group I, there were $29(38.2 \%)$ patients with C/C genotype, $39(51.3 \%)$ - with C/G genotype, and $8(10.5 \%)$ - with $\mathrm{G} / \mathrm{G}$ genotype. The distribution in group I was as following: 16 were homozygous for the $C$ allele $(18.8 \%), 40$ were heterozygous $(47.1 \%)$ and 29 were homozygous for the G allele $(34.1 \%)\left(x^{2}=15.23 ; p=0.02\right)$. It was established that the risk of ischemic heart disease was 6.57 times higher in homozygotes for the $\mathrm{G}$ allele (OR=6.57; $95 \% \mathrm{Cl}=2.44-17.73 ; \mathrm{p}=0.001)$ as compared with homozygotes for the $\mathrm{C}$ allele.

Conclusions: It was established that $\mathrm{G} / \mathrm{G}$ genotype prevailed in RA patients with ischemic heart disease, while $\mathrm{C} / \mathrm{C}$ genotype prevailed in patients with isolated $\mathrm{RA}$. The risk of IHD development in patients with RA was associated with $\mathrm{G} / \mathrm{G}$ genotype for Bcl1 polymorphism in the GR gene.

Disclosure of Interest: None declared

DOI: 10.1136/annrheumdis-2017-eular.3998

\section{SAT0137 BONE MINERAL DENSITY MEASUREMENT INTERVALS FOR SEROPOSITIVE RHEUMATOID ARTHRITIS PATIENTS NOT TREATED FOR OSTEOPOROSIS}

W. Park, K.-H. Jung, S.-R. Kwon, M.-J. Lim, S.-G. Park, M.-J. Jo. In-Ha University Hospital, Incheon, Korea, Republic Of

Background: Osteoporosis occurs more frequently in rheumatoid arthritis (RA) patients than in healthy individuals. However the appropriate interval for the bone mineral density (BMD) measurement in RA patients is not well established.

Objectives: This study investigated the effective BMD measurement interval and the risk factors associated with the development of osteoporosis for RA patients. Methods: A retrospective study was performed on 511 RA patients aged more than 40 years old who had undergone BMD (DXA, GE LUNAR PRODIGY ADVANCE) testing more than once and who had normal BMD or osteopenia at the baseline BMD test and no history of any fracture of the spine or femur. The subjects were categorized into four subgroups: normal BMD (T-score $>-1)$, mild $(-1 \geq$ T-score $>-1.5)$, moderate $(-1.5 \geq T$-score $>-2)$, and advanced $(-2 \geq T$-score $>-2.5)$ osteopenia. The BMD testing interval was defined as the estimated time for $10 \%$ of the RA patients to make the transition into osteoporosis without osteoporotic fracture or the administration of any osteoporosis drug.

Results: The observation period was 2,214 patient-years, with an average of 4.3 years. The estimated BMD testing interval was more than 10 years for normal, 4.3 years for mild, 2.5 years for moderate, and 1.5 years for advanced osteopenia in each of the RA patient groups.

Conclusions: Our study indicated that in normal or osteopenic RA groups, a baseline BMD T-score is the most important factor in estimating the interval in which osteoporosis is predicted to occur. In addition, we recommend that the BMD measuring interval should be greater than 10 years in normal BMD RA 